\title{
Pamela Mason and Tim Lang: Sustainable diets: how ecological nutrition can transform consumption and the food system
}

\author{
Routledge, Oxon, UK, 2017, 353 pp, ISBN 978-0-415-74472-0
}

\author{
Kathleen Kevany ${ }^{1}$ (1)
}

Accepted: 12 September 2017 / Published online: 16 October 2017

(c) The Author(s) 2017. This article is an open access publication

Sustainable diets are complex. The recently released Sustainable Diets offers a comprehensive study on sustainable diets through extensive analyses of relevant and disparate bodies of literature. Known also as respected authorities and ardent advocates for sustainable food systems, authors Mason and Lang meticulously document the subtle and complex factors of quality, health, environment, social values, economy and governance. They urge readers and system actors to distinguish 'values-for-money' rather than 'value for money'. The authors examine profound questions like, "...what could be more important than the nature, quality and sufficiency of diet for the planet?" (p. 2). They challenge readers-scientists, civil society actors, industry and governments - to examine what is a good diet? Is it possible to eat well for both environmental and bodily health? Can this be done in a culturally acceptable manner? Is it affordable by all? The issues are simultaneously technical, cultural, political, social, ethical, spiritual, economic, and environmental. Central messages of this book are that hesitation appears in the place of leadership as disparate fields often speak at cross-purposes yet creative systemic change is urgent. In spite of adherence to the philosophy of "let the market dictate," consumers cannot be saddled with sole responsibility in a climate of opaque and misrepresentative marketing. "What humanity eats has major impacts on public health, the economy, the environment and the future" (p. 9). It is unsurprising then that in "2012, the global economic cost of obesity was estimated to be around $\$ 2$ trillion, roughly

Kathleen Kevany

kkevany@dal.ca

1 Department of Business and Social Sciences, Faculty of Agriculture, Dalhousie University, Humanities House, 56 Rock Garden Road, Truro, NS B2N 3E5, Canada equivalent to the global cost of smoking or armed conflict" (p. 330).

The authors emphasize that non-communicable diseases are worsening worldwide, resulting in an immense "drag on economic "efficiency"' (p. 16). Still an array of conventions, conferences and reports reveal growing international agreement that change is imperative. A plethora of studies lead the authors to conclude that reduced ruminant and dairy consumption will be indispensable for reaching sustainable development goals and particularly of limiting global temperature rise of less than $2{ }^{\circ} \mathrm{C}$ above pre-industrial levels (p. 151). The authors recommend the adoption of principles, guidelines and a complex set of "omni-standards" or "poly-values" and tools to measure GHG emissions, land use, energy and water, among other indices. In Chapter Five readers are reminded of the many cultural and social factors influencing diets like cultural identity, habits, family practices and acceptability of food, like time pressures often trumping health and environmental considerations. "No matter how good a diet is for health and the environment, if it is not available to everyone in a form that is culturally appropriate such a diet cannot be judged sustainable" (p. 168). The authors effectively underscore the role of systematic forces, like advertising, and how they are molding food consciousness. In effect, "[t]elevised food adverts, which encourage viewers to eat the foods promoted for sale, constitute a de facto set of dietary endorsements" (p. 186).

These authors make substantive calls to action in this text for business, governments, and civil society based on the most recent research. For example, food quality is discussed in Chapter Six with elaborate detail: sensory attributes, safety, nutritional value, functionality, service and stability, healthfulness, authenticity, along with psychological factors, the production process, the value of food, and the importance of connections between consumers and producers. Chapter 
Seven on Real Food Economics questions how sustainable diets can become desirable (p. 210). "How can one calculate the loss of a view of the sky from a window or of prime agricultural land being covered by a housing estate or factory or the destruction of a species?" (p. 243). Readers are guided to consider important questions like what is a good life or society, who is doing domestic cooking and is this a good thing? And what is land for and how many people can be fed per hectare? The authors state that the price of food fails to convey true costs of production and consumption in terms of the environment, public health and the burden of waste. They masterfully describe the devastating biodiversity loss, water pollution, and increasing greenhouse gas emissions contributing to climate change. In Chapter Eight, this critical text examines the neo-liberal consumer choice edict and the role of food governance in transitioning to sustainability. They provide an interesting overview of the distinct phases of USA dietary guidelines that shifted their focus over time from children, to "protective foods" and "good eating" (1940s), to "fitness" and "'hassle-free food" (1950s-1970s), and then to "choice" (1980s), "adequacy and moderation" (1990s) and "healthy eating" (2000s) (p. 271). The authors lament insufficient critique of current dietary patterns and how disparate interventions fail to alter the status quo. They suggest that the "consuming public needs help to redefine what is acceptable and unacceptable, to recalibrate 'disgust', perhaps, as well as pleasure, and to set new norms and habits in everyday behavior" (p. 221). To facilitate the needed transitions, Mason and Lang urge interdisciplinary collaborative efforts among natural and social sciences, arts and culture, policy makers and providers, national and municipal governments, businesses, and NGOs. They recommend partnering with municipal structures and subjecting food sustainability and performance to public accountability and internal political review.

Areas of limitation in this text are few but worth noting. More attention should be paid to the love of, pleasure from, and the succulence of food. Readers looking for rich content on innovations around functional foods or plant-based businesses may not find as much as desired. As well more attention to spiritual dimensions of food would enhance it, such as the explanation of rice holding spiritual meaning, believed to be a medium between earthly and godly realms (p. 184). While these authors cover the ill health connected to unsustainable diets-including dementia or depression-the health chapter lacks reference to the psychological and physical harm experienced by workers in slaughterhouses and in precarious, low-paying food system jobs. Given the limitations inherent in developing a single book, opportunities remain for other writers to explore business and economic opportunities in emerging sustainable diets. This comprehensive book offers many answers particularly that the "cultural transition" (p. 193) must not be market driven—vision, leadership, including regulation and accountability are essential.

Open Access This article is distributed under the terms of the Creative Commons Attribution 4.0 International License (http://creativecommons.org/licenses/by/4.0/), which permits unrestricted use, distribution, and reproduction in any medium, provided you give appropriate credit to the original author(s) and the source, provide a link to the Creative Commons license, and indicate if changes were made.

Kathleen Kevany is an Associate Professor at Dalhousie University researching on factors that meditate individual and community wellbeing and movements towards sustainability and sustainable diets and she is the Director of the Rural Research Centre 